\title{
Luchas sindicales en la agricultura californiana, en la década de los treinta
}

\section{Union Struggles in California's Agriculture in the $1930 \mathrm{~s}$}

\author{
Rosa Verónica Zapata Rivera \\ (D) https://orcid.org/0000-0003-4873-1075 \\ Facultad de Ciencias Políticas y Sociales \\ Universidad Nacional Autónoma de México, México \\ verozari@gmail.com
}

Resumen: En este artículo se revisarán dos de los momentos más significativos de las luchas sindicales agrícolas en California durante las primeras tres décadas del siglo xx. Se tiene por objetivo mostrar cómo mediante la coordinación de acciones entre distintos actores e instancias se logró iniciar el camino hacia lo consolidación del mercado laboral agrícola californiano, donde los intereses agroindustriales prevalecieron sobre los de los trabajadores, no sin importantes confrontaciones y desencuentros.

Palabras clave: trabajadores agrícolas mexicanos en California; sindicatos; huelgas; consulado; agroindustriales.

Abstract: This paper will review two of the most significant moments of agricultural union struggles in California during the first three decades of the 20th century. The goal is to show how, through the coordination of actions between various actors and instances, it was possible to embark on the road towards the consolidation of the Californian agricultural labor market, where agro-indus-

cómo citAr: Zapata Rivera, R. V. (2022). Luchas sindicales en la agricultura californiana, en la década de los treinta. Secuencia (112), e1813. Dor: https://doi.org/10.18234/secuencia.v0i112.1813

CC 8 Esta obra está protegida bajo una Licencia Creative Commons Atribución-NoComercial 4.0 Internacional. 
trial interests prevailed over those of workers, not without significant confrontations and disagreements.

Keywords: Mexican agricultural workers in California; unions; strikes; consulate; agro-business.

Recibido: 28 de enero de 2020 Aceptado: 16 de noviembre de 2020 Publicado: 9 de febrero de 2022

$\mathrm{C}$ alifornia se distingue como uno de los estados de mayor producción agrícola en Estados Unidos. Para entender la bonanza de esta industria, se debe tener en cuenta que desde el siglo XIX vivió un proceso de transformación cuando "La agricultura como medio de vida, cedió paso a la agricultura como negocio" (Morison et al., 1995, p. 492).

Este cambio de modelo productivo generó una forma distinta de competencia y de inversión. Las industrias relacionadas con el mercado agrícola se fortalecieron, los fabricantes de insumos, maquinaria, intermediarios, procesadoras y financiadoras se convirtieron en actores fundamentales y, en gran medida, su desarrollo fue posible gracias a que el Estado invirtió en la construcción de infraestructura para almacenamiento de agua, sistemas de riego, así como en la creación de dependencias encaminadas a su investigación y administración.

De esta forma, la tecnificación de sus procesos y la producción intensiva de monocultivos de temporada requirió de mano de obra abundante y fácil de movilizar, esa fuerza de trabajo estuvo constituida inicialmente por filipinos, chinos y japoneses, pero por las leyes de exclusión de carácter nativista, suscritas a finales del siglo xIx y principios del $\mathrm{xx}$, disminuyeron su presencia, mientras que la vecindad de los mexicanos permitió mantener un constante cruce transfronterizo que, con el paso del tiempo, los posicionó como la principal fuente de trabajadores agrícolas para ese país.

Antes de la crisis del 29, la política agrícola estadunidense se había concentrado en el desarrollo de infraestructura con el objetivo de satisfacer las demandas del mercado interno (Amstutz, 1985, p. 322), con el gobierno de Roosevelt durante la puesta en marcha del llamado "primer New Deal", ${ }^{1} \mathrm{y}$

${ }^{1}$ Fraser (2010) menciona que esta es una categoría utilizada por algunos historiadores para distinguir dos momentos en el New Deal, el primero con acciones contenidas que busca- 
bajo la Ley de Ajuste Agrícola firmada en 1933 "subvencionaron la actividad agraria garantizando los precios al productor, comprando los excedentes o pagando a los agricultores para que no produjeran” (Hobsbawm, 2014, p. 102).

De esta manera, el respaldo que el Estado dio a la industria agrícola fue clave para consolidar su poder económico y político y permitir la existencia de un mercado laboral no regulado, donde la carencia de derechos laborales propició que desde las primeras décadas del siglo $\mathrm{xx}$ detonaran incipientes intentos de organización sindical.

En este artículo revisaré algunos de los momentos más significativos de la organización sindical agrícola de California, Estados Unidos, durante la década de los treinta. Si bien, este ha sido un tema ampliamente estudiado, sobre todo en Estados Unidos, en este trabajo me ocuparé de observar, en los procesos abordados, el arsenal de operaciones coordinadas entre distintas instancias, como las acciones violentas, el desprestigio de organizadores sindicales y funcionarios consulares mexicanos, el establecimiento de relaciones de complicidad entre actores, y la construcción de estereotipos usados tanto por empleadores como por funcionarios, clave en lograr la desarticulación sindical y el control de ese mercado laboral.

Las primeras reflexiones sobre los trabajadores mexicanos en la agricultura californiana nacieron sobre todo de antropólogos, economistas, sociólogos, politólogos, periodistas e incluso novelistas, quienes centraron su atención al iniciar el siglo xx en el análisis de la agricultura corporativa, el mercado laboral, los acuerdos migratorios, la formación de comunidades mexicanas, incluso en las condiciones laborales y de vida de los trabajadores. ${ }^{2}$ Asimismo, a partir de la década de los ochenta algunos historiadores, e incluso desde la geografía marxista, ${ }^{3}$ continuaron estas reflexiones resaltando la importancia de los mexicanos en la historia laboral estadunidense.

ban mantener el respaldo de las elites económicas, al impulsar la colaboración público-privada; mientras que el segundo New Deal se caracterizó por implementar "reformas más valientes y de inspiración socialdemócrata" (p. 13), desarrolladas a partir de 1935.

${ }^{2}$ Véase Manuel Gamio, Paul S. Taylor, Henry Anderson, Ernesto Galarza, Carey McWilliams, John Steinbeck, Varden Fuller, entre otros.

${ }^{3}$ Cletus (1981) investigó sobre las luchas laborales en la agricultura de California durante las primeras décadas del siglo $\mathrm{xx}, \mathrm{y}$ resalta la importancia de los mexicanos como trabajadores de campo. Weber $(1986,1996)$ y su posterior libro Dark sweat, white gold California farm workers, cotton, and the New Deal, en ambos textos, reivindica la importancia de los trabajadores agrícolas mexicanos transnacionales en la organización sindical de las huelgas agrícolas de la década de los treinta, sobre todo, en el valle de San Joaquín. Habla de ellos como actores activos que inter- 


\section{LA ORGANIZACIÓN SINDICAL}

1933 se configuró como uno de los años más intensos para la organización sindical agrícola de California, ${ }^{4}$ a la cual se oponían férreamente los productores de esta industria. La Cannery and Agricultural Workers Industrial Union $(\text { CAWIU })^{5}$-sindicato de filiación comunista-, fue un grupo importante de estos movimientos laborales. Su nacimiento fue el resultado de un cambio de dirección política de la Internacional Comunista durante su Sexto Congreso Mundial celebrado en Moscú, en 1928. Ahí, Stalin, enfrascado en una lucha por el poder con Nicolai Bukharin, habló de un "Tercer Periodo" en el desarrollo del capitalismo, de su colapso económico y de una posible confrontación de países capitalistas contra la Unión Soviética. Ante este pronóstico, más que establecer alianzas de clase, buscó reclutar miembros de organizaciones de izquierda y sindicales al Partido Comunista, así se convertiría en el único líder del proletariado unificado (Cherny, 2002, p. 9).

De esta forma decidieron crear sus propias organizaciones y trabajar directamente con grupos explotados como los trabajadores agrícolas. En esa lógica, en 1929, el Partido Comunista de Estados Unidos formó la Trade Union Unity League (TUUL) como una confederación sindical y se dispuso a organizar sindicatos duales en varias industrias. Es en ese contexto como nació el CAwIU (Cherny, 2002, pp. 9-10). En ese sentido, los trabajadores precarizados, temporales y extranjeros que habían sido rechazados por sindicatos blancos y conservadores como la American Federation of Labor (AFL), representaron una potencial fuerza revolucionaria que había sido segregada por su pertenencia étnica y que estaba pasando -como el resto de los traba-

pelan al poder. Gilbert G. González (1994), muestra a la comunidad de migrantes mexicanos en la industria de los cítricos en California. En 1999 publica Consuls and labor organizing: Imperial politics in the American southwest, donde analiza la participación coordinada de los cónsules mexicanos con los agricultores en un intento por terminar con cuatro importantes huelgas de trabajadores agrícolas durante la década de los treinta. Don Mitchell (1996) reflexiona desde la geografía sobre la organización sindical en la década de los treinta, sobre las confrontaciones físicas e ideológicas entre empleadores y empleados y la lucha por el control de las condiciones de trabajo y de vida, las cuales incidieron en la construcción del paisaje de California durante el siglo xx.

${ }^{4} \mathrm{Y}$ el momento en el cual los mexicanos se convirtieron en la columna vertebral para los impulsos sindicales de la década -sobre todo de 1933 a 1937- (Weber, 1986, p. 300).

${ }^{5}$ Se constituyó en 1930 con el nombre de Agricultural Workers Union, cambió su nombre a CAWIU en 1931. Formó parte del grupo de sindicatos organizados por la Trade Union Unity League (TUUL). 
jadores en Estados Unidos- por la desesperanza del desempleo y los bajos salarios que había traído consigo la gran depresión.

\section{LA HUELGA DEL ALGODÓN}

Una de las huelgas más importantes organizadas por el cawiu fue la del algodón, que estalló el 4 de octubre de 1933 en el Valle de San Joaquín. La exigencia del sindicato y los trabajadores giraba en torno a tres puntos: el aumento salarial de .60 centavos a un dólar por 100 libras de algodón cosechado; la contratación de los trabajadores vía la mediación del sindicato, y la abolición del sistema de contratistas, esto es, dejar de usar intermediarios para la contratación de trabajadores. ${ }^{6}$ En ella participaron entre 15000 y 18000 trabajadores; los primeros brotes de organización comenzaron en los condados del sur en Kings, Kern y Turale, y se fue extendiendo a los condados del norte en Madera, Fresno, Merced, Stanislaus y San Joaquín (Barry, 1938, p. 76); conforme la huelga cobraba más importancia las confrontaciones se hacían más violentas (véase mapa 1).

Una de las causas atribuidas a la huelga es la ya mencionada disminución salarial que los cosechadores habían experimentado de forma dramática. En 1928 y 1929 se pagaba entre 1.50 y 1.45 dólares por 100 libras de algodón cosechado, en comparación con los .40 centavos que se pagaron en 1932, y los .60 centavos de 1933 por la misma cantidad de algodón cosechado (Barry, 1938, p. 3; Chacon, 1984, p. 345) (véase gráfica 1).

A la par de la disminución salarial, algunas políticas estatales creadas por el New Deal fueron clave en el fortalecimiento de industrias como esta, cuyos ranchos productores de California fueron privilegiados por la mayoría de los subsidios entregados por la Ley de Ajuste Agrícola. De esta forma, "dieron beneficios desproporcionados a los grandes granjeros, y la campaña por la reducción de las cosechas incluso expulsó de los campos a algunos de los -pequeños- aparceros" (Morison et al., 1995, p. 679).

Además, los grandes productores, así como las empresas desmontadoras de algodón que en ocasiones funcionaban como filiales de una misma compañía (como Anderson Clayton \& Co., o J. G. Boswell \& Co.), controla-

${ }^{6}$ Este pliego petitorio -aumento salarial, eliminación de los contratistas y reconocimiento sindical- fue repetido de forma constante en otras huelgas. 


\section{Mapa 1. Condados de California donde se extendió la huelga del algodón en 1933}

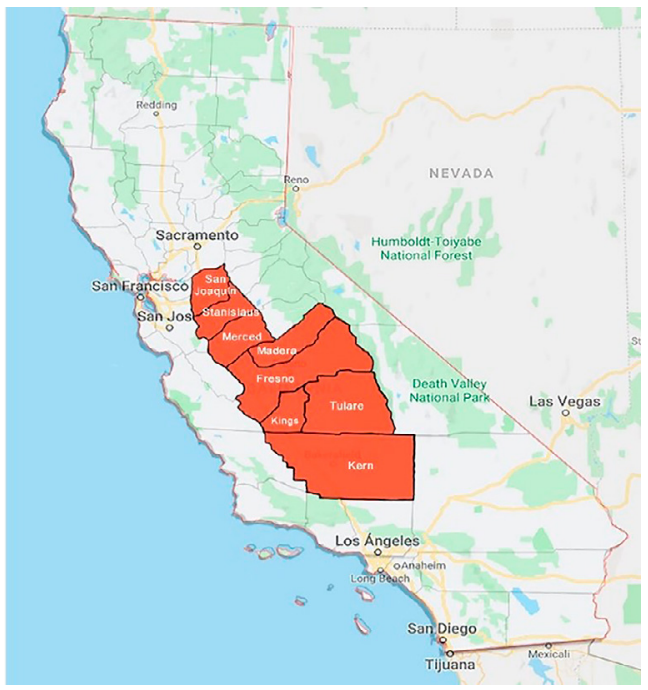

Fuente: elaboración propia a partir de Google Maps, 2019.

Gráfica 1. Disminución del salario de los cosechadores de algodón, 1928-1933

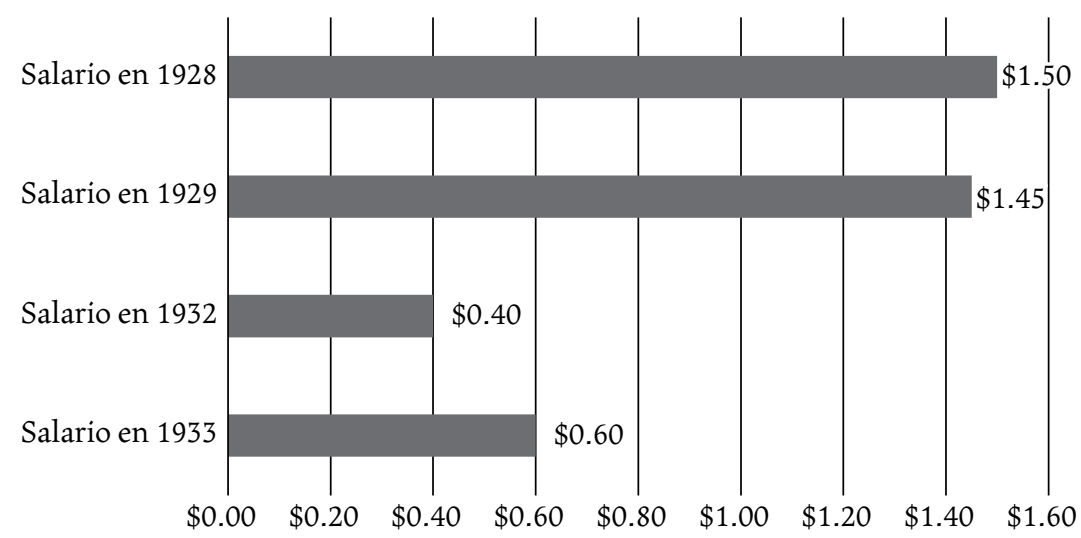

Fuente: elaboración propia con datos de Chacon (1984) y Barry (1938). 
ban el mercado y eran los que determinaban los costos de producción y los salarios de los trabajadores agrícolas antes del inicio de la temporada de cosecha, esto lo hacían a través de instancias u organizaciones regionales en las cuales participaban, como la Oficina de Trabajo Agrícola del Valle de San Joaquín (sJvalB) (Chacon, 1984, pp. 341, 343; Barry, 1938, pp. 3, 5-6).

Incluso advierten públicamente que los salarios se establecen no por los rendimientos o la venta de los cultivos, sino por la demanda general de mano de obra, donde ningún productor individual o pequeño grupo de productores puede fijar a su parecer una escala de salarios. ${ }^{7}$ Si lo hacían corrían el peligro de ser excluidos o llevados intencionalmente a la quiebra por los agroindustriales que controlaban las financiadoras o las productoras de insumos a las que pequeños productores recurrían en busca de créditos.

En ese contexto, la organización sindical representaba para los trabajadores una alternativa para escapar de la miseria, ya que, la constante disminución de los salarios, los orilló a sobrevivir por debajo de los niveles de pobreza, además de que la dinámica de cosecha que impone la siembra intensiva de monocultivos de temporada propicia que los trabajadores agrícolas se movilicen detrás de la temporada de recolección de cada producto.

El algodón en el Valle de San Joaquín se cosecha en el otoño, durante ese periodo un trabajador "nacido en el algodón" con experiencia en la pizca desde pequeño, recolecta en un día del pico de la temporada entre 500 o 600 libras de algodón -se puede inferir que si el pago que recibe es de .60 centavos por 100 libras, ese trabajador experimentado ganaba al día por una jornada de trabajo entre 3 y 3.6 dólares-, sin embargo, se estima que si un recolector promedio (con poca experiencia) pizca 200 libras y una recolectora 175 libras, se concluye que lo que cada uno gana al día es de entre 1.20 y .90 centavos de dólar (Barry, 1938, p. 5).

Para darnos una idea de los costos de vida durante ese mismo año, por ejemplo, unas botas de trabajo impermeables Henry Dermer costaban 3.95 dólares, el precio de la miel de panal era de 10 centavos por bote y una lavadora eléctrica de la marca Kenmore costaba 49.95 dólares de contado; sin embargo, los campos para trabajadores agrícolas temporales pocas veces contaban con servicios de electricidad, pero la misma marca tenía ese modelo para usar con gasolina, a 82.50 dólares, que equivalía a 27 días de trabajo de

${ }^{7}$ Gilbert H. Parker, "Communists Attack on Ranch Owners Explained in Detail”, Ukiah Republican Press, 15 de agosto de 1934, p. 1. 
un cosechador experimentado. Estos costos no le permitían a un trabajador agrícola acceder a este tipo de productos, y mucho menos podría haber disfrutado de las festividades anunciadas en la prensa, el Hotel Fresno ofrecía una cena baile de fin de año, con dos bandas y vino incluido por cinco dólares por persona. ${ }^{8}$

Por otro lado, la capacidad de organización de los trabajadores mexicanos fue cuestionada por funcionarios del gobierno estatal. Según el parecer del secretario ejecutivo del Consejo Agrícola de California, Ralph Taylor, "los 'mexicanos' eran naturalmente dóciles; y no tenían 'ambiciones políticas" (Mitchell, 1996, p. 91), también se les otorgó habilidades innatas para el trabajo agrícola: "Los empleadores, afirmaron que los mexicanos eran parte india y por lo tanto eran gente esencialmente rural, preferían el ambiente al aire libre y estaban contentos trabajando en granjas. Además, decían que eran pequeños, ágiles y nerviosos, y con las cualidades físicas necesarias, para realizar trabajos agrícolas" (Laittre, 1930, p. 106; Reisler, 1976, pp. 137-139, citados en Chacon, 1984, pp. 347 y 348 ).

Las representaciones racializadas ${ }^{9}$ sobre los mexicanos se usaron para colocarlos en estamentos alejados de las características que definían y daban identidad nacional estadunidense, al verlos como un "otro" inferior era mucho más sencillo excluirlos y explotarlos. "El grado al cual los mexicanos fueron racializados durante este periodo se manifiesta en el hecho de que la oficina del censo de Estados Unidos en 1930, por primera y única vez en su historia enumerara a los mexicanos como una raza por sí misma, junto a los negros" (Bean y Tienda, 1987 citado en Massey, 2008, p. 75). Según Leeman (2016, pp. 367-368), la definición oficial de esta categoría se refería a todas las personas nacidas en México o con padres nacidos en ese país, que no sean blancos, negros, indios, chinos o japoneses. La categoría racial "Mexican" fue eliminada de la encuesta censal aplicada durante 1940.

A estas adjetivaciones y a la extranjería que se les endilgaba por sus características fenotípicas percibidas, aunque fueran ciudadanos de segunda

\footnotetext{
${ }_{8}^{8}$ Información recabada de los periódicos The Fresno Bee, 24 de diciembre de 1933, p. 32; The Fresno Bee, 10 de septiembre de 1933, p. 48.

${ }^{9}$ Omi y Winant (2015) nos dicen respecto a la racialización que, mediante un complejo proceso de selección, las características físicas ("reales" o imaginarias) se convierten en la base para justificar o reforzar la diferenciación social [...] Este proceso mediante el cual se da significado social y simbólico a las diferencias fenotípicas percibidas, es el elemento central y constitutivo de lo que llamamos "racialización" (p. 111).
} 
o tercera generación, se sumó que los empleadores los trataban como a menores de edad. La activista y crítica de la agroindustria de California, Helen Hosmer, cuenta que durante su trabajo en la Administración de Seguridad Agrícola, un productor del Valle Imperial mencionó que "el único problema con los mexicanos es que quieren aprender todo sobre la maquinaria agrícola, y [...] realmente no puedes confiar en ellos para que toquen esas cosas. Siempre tenían que alejarlos [...] porque querían aprender [...] Pueden romperla" ${ }^{10}$

Sin embargo, fue la participación masiva de distintos actores en la huelga, como los mexicanos, lo que logró proporcionar al Partido Comunista $\mathrm{y}$ a las primeras luchas sindicales de principios del siglo $\mathrm{xx}$ un impacto significativo en la historia del movimiento laboral agrícola en California. Además, para algunos investigadores, ${ }^{11}$ los antecedentes de participación política de algunos de ellos en la revolución mexicana, en el Partido Liberal Mexicano, así como en los Trabajadores Industriales del Mundo (IWW), fue fundamental en su conocimiento sobre tácticas y estrategias de organización.

\section{LA VIOLENCIA EN LOS CAMPOS DE ALGODÓN}

La violencia se desbordó el 10 de octubre de 1933, en Pixley, en el condado de Tulare. Estaban reunidos un grupo de huelguistas escuchando al organizador sindical Pat Chambers, en un lote cercano a las oficinas del CAWIU -un edificio de ladrillo de dos pisos- cuando fueron interrumpidos por una caravana de autos donde viajaban cultivadores y vigilantes armados. Las fuentes hablan de diez, doce y hasta 30 automóviles que arribaron al lugar de la reunión. Según la narración, ante el ataque Chambers pidió a los huelguistas no inmiscuirse en confrontaciones. Los huelguistas trataban de resguardarse, mientras que agazapados, detrás de sus automóviles, los cultivadores abrieron fuego contra ellos. A la distancia los patrulleros y sheriffs observaron el ataque sin interferir (Barry, 1938, p. 18; Walker, 2012, p. 53; Weber, 1986, p. 179). ${ }^{12}$

El poder y la cercanía que los empresarios agrícolas tenían con los sheriffs y autoridades locales les permitió establecer este tipo de complicidades.

${ }^{10}$ Entrevista a Helen Hosmer en Jarrell (1992, p. 43).

${ }^{11}$ Como Daniel Cletus, Devra Weber, Gilbert Gimenez y Don Mitchell.

${ }^{12}$ Edward J. Heilman, "Mob of cotton strikers menaces jail; 3 slain in clashes with ranchers", Oakland Tribune, 11 de octubre de 1933, p. 1. 
Las fuerzas del orden no estaban dispuestas a entrar en controversia con ellos por trabajadores "extranjeros" sobre los que tenían muy poca simpatía.

En las notas de prensa posteriores al ataque, la nacionalidad fue una justificación para el uso de la violencia. El que dijo ser el ranchero que realizó el primer disparo, afirmó que antes de darlo había escuchado que alguien había hablado de forma despectiva de la bandera estadunidense ${ }^{13}$ En ese contexto la nacionalidad no sólo fue utilizada como exclusión, incluso permanecer o-presentarse- como extranjero a pesar del tiempo de residencia -o de haber nacido en ese país- fue una elección para las personas de origen mexicano. Balderrama (1982, p. 8) menciona que la conservación de la ciudadanía obedeció al temor que tenían a la sociedad angloamericana y a su deseo de protección consular -aunque este no siempre fuera efectivo. En ese sentido, podemos decir que las identidades sociales de grupos marginados -como los trabajadores agrícolas de origen mexicano- son impuestas tanto por grupos dominantes, como por instituciones estatales -empleadores y funcionarios- y establecidas desde abajo - por los subordinados- como un ejercicio de autoidentificación y resistencia a las categorías y formas predominantes (Omi y Winant, 2015, p. 106), en ese sentido la "extranjería" que les endilgaban era también una estrategia del subordinado para apelar al amparo consular ante una sociedad y un estado hostil.

Después del ataque el saldo fue de dos muertos: Delfino Dávila, de 55 años, quien recibió un disparo en el rostro y era representante del consulado mexicano en Tulare, y Dolores Hernández, de 50 años, trabajadora del rancho Tagus donde dos meses antes había estallado la huelga del durazno. Además, siete hombres y una mujer fueron heridos. Entre los arrestados se habló de once a doce productores, quienes se justificaron afirmando que desde el cuartel general de huelga habían recibido los primeros disparos. Después de este incidente fueron arrestados cinco vigilantes, así como Pat Chambers junto con 16 trabajadores bajo el pretexto de perturbar la paz. ${ }^{14}$

${ }^{13}$ Barry (1938, p. 20); Edward J. Heilman, "Mob of cotton strikers menaces jail; 3 slain in clashes with ranchers", Oakland Tribune, 11 de octubre de 1933, p. 1. La recolección de algodón en el Valle de San Joaquín estaba bajo el monopolio de los mexicanos que comprendían entre 75 y $95 \%$ de los cosechadores, otro tanto estaba conformado por filipinos, algunos afroamericanos y pequeños productores y aparceleros blancos que venían de las planicies del sur y que habían perdido sus tierras (Mitchell, 1996, pp. 142-143 citado por Walker, 2012, p. 50).

${ }^{14}$ Barry (1938, p. 21); Weber (1986, p. 180); Edward J. Heilman, "Mob of cotton strikers menaces jail; 3 slain in clashes with ranchers", Oakland Tribune, 11 de octubre de 1933, p. 1. 
La violencia había estallado en la zona algodonera. El mismo día de los enfrentamientos de Pixley, pero a 67.6 millas de distancia, en la ciudad de Arvin, del condado de Kern, explotó la gresca derivada de cinco horas de intercambio de bromas e insultos entre productores y huelguistas. Entre $25 \mathrm{y}$ 30 productores y vigilantes armados con rifles se enfrentaron a 250 huelguistas armados con estacas de madera utilizadas para los viñedos. Los alguaciles que acompañaban a los productores lanzaron gases lacrimógenos tratando de disipar a los manifestantes; mientras los productores disparaban sus armas, varios resultaron heridos. Según los datos, un productor abrió fuego y mató al instante, de un disparo en el pecho, a Pedro Subias, un huelguista mexicano de 57 años. Sin embargo, testigos afirmaron que Pedro fue fusilado al recibir once disparos cuando yacía en el piso. Los productores intentaron desmentirlo al decir que fue otro compañero huelguista el que le disparó, tal vez por error, desde un árbol cercano (Barry, 1938, p. 24; Weber, 1986, p. 179).

Lo cierto es que Pedro Subias era un veterano en la organización sindical, originario de Chihuahua, y había migrado desde muy joven a Arizona donde trabajó en la minería y se involucró en la huelga del cobre de las minas Clifton y Morenci, y en la década de los años veinte se mudó a California donde se incorporó en el trabajo agrícola (Acuña, 2007, p. 208).

Al día siguiente de los asesinatos, la prensa documentó cómo las grescas dejaron al Valle en un estado inquieto y temeroso, los funcionarios procedieron con cautela ante los asesinatos, los productores se reunieron en privado y los cosechadores se congregaron afuera de la cárcel del condado de Tulare para exigir la liberación de los detenidos acusados por cargos de disturbios.

Las acciones de los recolectores no se limitaron a las protestas, el comité de huelga envío al gobernador de California, James Rolph, quien mostraba abierta simpatía hacia los agricultores, una serie de demandas donde pedían, entre otras cosas, enjuiciar a los ganaderos responsables del asesinato de trabajadores desarmados. ${ }^{15}$

Asimismo, la participación del consulado mexicano ${ }^{16}$ en dichas rencillas no fue menor. A principios de octubre de 1933 el cónsul general de San

15 "Governor Rolph rejects five of six demands of striking cotton pickers", Santa Cruz Sentinel, 14 de octubre de 1933, p. 1.

${ }^{16}$ Respecto a los reglamentos que regían las acciones de los consulados, Balderrama (1982) nos dice que tanto la Ley Orgánica del Cuerpo Consular Mexicano y el Reglamento de la Ley Orgánica del Servicio Consular Mexicano, de 1923 y 1934, respectivamente, determinaban que los cónsules debían "proteger los intereses y derechos de los mexicanos nacionales", era su 
Francisco, Alejandro Lubbert, comisionó al entonces cónsul de Monterrey, Enrique Bravo, a ir por un periodo de 24 días al Valle de San Joaquín para visitar los lugares afectados por la huelga de trabajadores agrícolas mexicanos. ${ }^{17}$

Además, Enrique Bravo consideró el asesinato de Delfino Dávila, trabajador del consulado mexicano en Tulare, un asunto de carácter internacional. Telegrafió al gobernador pidiendo el desarme de los agricultores, y a pesar del rechazo abierto de Bravo a la violencia ejercida contra los mexicanos, se opuso a la lucha de clase tratando de persuadirlos para que desertaran del cawiu y formaran un sindicato de carácter nacional; sus intentos fracasaron. Pero la organización sindical, lejos de desmoronarse, se consolidó en un sentimiento de unidad de clase (Walker, 2012, p. 55; Weber, 1986, pp. 180-182).

La actividad de Bravo para que los mexicanos no se adhirieran al cAwIU fue incluso tan férrea que cuando la Secretaría de Relaciones Exteriores decidió que dejara su puesto como cónsul de Monterrey, en 1935, recibió cartas por parte de algunos funcionarios del gobierno, como el sheriff del condado de Fresno, Geo J. Overholt, ${ }^{18}$ y el jefe de la policía de la ciudad de Fresno, Frank Traux, ${ }^{19}$ solicitando su restitución, así como de la Comisión Honorífica Mexicana $^{20}$ que daba como justificación dicha postura anticomunista: "La colonia mexicana está muy satisfecha con la labor desarrollada por el C. Consul [sic] Enrique Bravo, durante las huelgas de 1933 en las que los lideres [sic] Comu-

deber brindarles asistencia sobre las leyes del país anfitrión, intervenir en disputas civiles, casos criminales, en la investigación de muertes, en la revisión de contratos de trabajo, ayudarlos en caso de accidente a obtener compensaciones, y prevenirlos de las compañías que no cumplían sus contratos (pp. 6-7).

${ }_{17}$ Memorándum del jefe del Departamento, Lic. Anselmo Mena, al jefe de Departamento de Administración y Archivos. 9 de noviembre de 1933. Expediente personal de Enrique Bravo. Tercera parte. Número 4-20750, exp. IV-P/131/; Memorándum del jefe del Departamento, Daniel Orozco, al jefe del Departamento Consular. 27 de noviembre de 1933. Expediente personal de Enrique Bravo, 3a. parte, núm. 2-10729, exp. II/123.21(73-95)33/2. Archivo Histórico Genaro Estrada, Secretaría de Relaciones Exteriores (en adelante AHGE-SRE), México.

${ }_{18}$ Cablegrama del Sheriff del condado de Fresno, Geo J. Overholt, a la Secretaría de Relaciones Exteriores, 19 de enero de 1935, expediente personal de Enrique Bravo, 1a. parte, núm. 2338, exp. III/131/10373, AHGE-SRE, México.

${ }^{19}$ Cablegrama del jefe de la policía de la ciudad de Fresno, Frank Truax, a la Secretaría de Relaciones Exteriores, 19 de enero de 1935, expediente personal de Enrique Bravo, 1a. parte, núm. 2337, exp. III/131/10373, AHGE-SRE, México.

${ }^{20}$ Los miembros de la Comisión Honorífica servían como representantes oficiales del consulado ante la colonia mexicana y la comunidad estadunidense, también ayudaban a los mexicanos en sus quejas y reclamaciones; les hacían visitas en la cárcel, los hospitales, las escuelas, las fábricas y en el campo (Balderrama, 1982, p. 184). 
nistas, engañaban a los mexicanos para que se unieran a ellos, el cónsul [sic] Bravo trabajó muy activamente ilustrando a los mexicanos, sobre el fin que... perseguíaan [sic]."21

A pesar de los esfuerzos coordinados desde distintas instancias, el sentimiento de unidad no se pudo desarticular y se hizo latente durante los funerales de los sindicalistas asesinados en las confrontaciones en las ciudades de Pixley y Arvin, y fue la ocasión perfecta para mostrar el descontento y la unión de los trabajadores. En Pixley, 5000 recolectores en huelga se unieron en un cortejo fúnebre hacia el cementerio acompañando los cuerpos de Dolores y Delfino. El periódico San Francisco Examiner lo describió como una procesión militar (15 de octubre de 1933, citado en Barry, 1938, p. 23).

En el condado de Kern, el funeral de Pedro Subias se convirtió en un mitin donde diferentes oradores hablaron de su intensa actividad sindical en Arizona y en California, de su trágica muerte a manos de los granjeros, al tiempo que largas filas de compañeros huelguistas esperaban para pasar delante del féretro y despedir a su compañero de lucha. En la reunión se observaron carteles con consignas que exigían la liberación de los sindicalistas presos y proclamaban: las balas no pueden vencernos. ${ }^{22} \mathrm{Al}$ finalizar la huelga del algodón, los detenidos de ambas facciones fueron liberados y ningún productor fue enjuiciado por la muerte de los huelguistas.

Además de usar la violencia física buscaron desmoralizar al movimiento mediante el hambre, apenas habían transcurrido ocho días del inicio de la huelga y las condiciones de los trabajadores eran insostenibles. Según el periódico Santa Cruz Sentinel, entre las seis demandas que el comité de huelga había hecho al gobernador estaba la de solicitar alimentos para los huelguistas hambrientos. ${ }^{23}$ Tan sólo del lunes 9 al miércoles 15 de octubre habían muerto cinco bebés, de entre tres y nueve meses de edad, a causa de la desnutrición. Y unos días antes de finalizar la huelga se reportó la muerte de nueve personas por inanición. Este panorama fue propicio debido al uso estratégico de la

${ }^{21}$ Carta de la Comisión Honorífica Mexicana a la Secretaría de Relaciones Exteriores, enero de 1935, expediente personal de Enrique Bravo, 1a. parte, núm. 3936, exp. III/131/10373, AHGE-SRE, México.

22 "Funeral for riot victim held in city", The Bakersfield Californian, 16 de octubre de 1933, pp. 1 y 9.

${ }_{23}$ "Governor Rolph rejects five of six demands of striking cotton pickers", Santa Cruz Sentinel, 14 de octubre de 1933, p. 1. 
prestación de asistencia alimentaria a cambio del compromiso de abandonar la huelga (Barry, 1938, pp. 41-42).

Se debe enfatizar que los trabajadores agrícolas se encontraban en constante movimiento ya que sobrevivían con los ingresos obtenidos en la cosecha de distintos productos, la precariedad de sus salarios no les permitió tener ahorros para dejar de trabajar en caso de algún imprevisto como por enfermedad, el trabajo se caracterizaba por la participación de cada miembro de la familia, y por lo general debían combinar su actividad en el campo con otras labores fuera de cada temporada.

Si la alimentación o la enfermedad resultaba difícil de solventar durante una huelga, la muerte significaba el endeudamiento y un mayor empobrecimiento. El cuerpo de Pedro Subias no había sido llevado al cementerio ya que aún se realizaba la colecta para lograr costear los gastos del entierro. El director de la Junta de Supervisores de Kern, que es el cuerpo legislativo y ejecutivo del condado, J. Perry Brite, había pedido al condado que costeara lo gastos del entierro.

En ese entonces una parcela en el cementerio costaba 40 dólares y los gastos del funeral $85-y$ ante un salario raquítico el pago resultaba irrisorio-. Brite propuso que "si su familia no tiene fondos, podemos enterrarlo como indigente", para ello el condado posee una parcela en el cementerio, y los cargos funerarios serían sólo de 36 dólares ${ }^{24} \mathrm{La}$ alternativa de una fosa común para un huelguista experimentado fue un desprecio de clase.

Así, podemos observar que el uso a discreción de las competencias del Estado para favorecer, o para debilitar moralmente a los huelguistas, es un ejercicio de violencia estructural a partir de construcciones sociales que son utilizadas para excluir, como la nacionalidad, la raza o las clases sociales. En este sentido, retomo el análisis desde la interseccionalidad de Omi y Winant (2015, p. 107), donde la raza es vista como un principio organizador fundamental de la estratificación social. Que además ha influido en la definición de derechos y privilegios, en la distribución de recursos y en las ideologías y prácticas de subordinación y opresión.

Después de la escalada de violencia en las ciudades de Pixley y Arvin, y ante el rechazo de la opinión pública, se llegó a un aparente punto muerto. El gobernador Rolph ideó una serie de estrategias para tratar de finalizar la

24 "Funeral for riot victim held in city", The Bakersfield Californian, 16 de octubre de 1933, p. 9. 
huelga, por un lado, solicitó a las agencias federales aumentar la ayuda para los agricultores, lo cual consistía en incrementar un centavo por libra sobre el precio del algodón, por otro lado, solicitó que la asistencia alimentaria que el gobierno federal daba a los huelguistas por medio de la National Recovery Administration fuera suspendida, ya que a su parecer la federación debía dejar de alimentar a esos "becarios o nunca trabajarán”, también le pareció adecuado que extranjeros indeseables fueran deportados de las áreas algodoneras. ${ }^{25} \mathrm{El}$ condicionamiento de la ayuda alimentaria a los huelguistas fue una práctica generalizada que dejó de ser utilizada unos días antes de finalizar la huelga.

\section{JUAN SÁNCHEZ, UN TRABAJADOR AGRÍCOLA}

Pero, en términos generales, ¿cuáles eran las condiciones de los trabajadores agrícolas? El 31 de marzo de 1998, Harvey Schwartz (1998) entrevistó a Juan Sánchez, en Petaluma, para el proyecto de historia oral del Labor Archives and Research Center, de la Universidad Estatal de San Francisco. Algunos aspectos de la vida de Juan son clarificadores sobre las condiciones de los trabajadores agrícolas y sus familias.

Juan Sánchez nació en el condado de Tulare, California, el 6 de mayo de 1920, fue hijo de padres mexicanos dedicados a trabajar el campo californiano. Había pasado su infancia en constante movimiento tras las temporadas agrícolas. Recuerda que a los cuatro o cinco años pizcaba algodón junto a sus padres. Cuando no era temporada de cosecha, su madre María Sánchez trabajaba como empleada doméstica, y su padre, Pedro Sánchez, en el ferrocarril.

Se establecieron en Pixley para que él y su hermana asistieran a la escuela. Vivió en una zona conocida como squatters village, que él mismo describe como pequeñas chozas de cartón sin electricidad, utilizaban velas, y su estufa era una lata grande que llenaban de leña y sobre ella colocaban una plancha de metal. Habitaron ese lugar hasta 1935. Cuando terminó la escuela primaria un agricultor les prestó una destartalada casa de madera donde las condiciones no eran muy diferentes, seguían sin alumbrado, sin agua potable y con letrinas donde abundaban las viudas negras.

${ }_{25}$ "State highway officers rule cotton strike area; Rolph acts deadlock", Okland Tribune, 24 de octubre de 1933, p. 1. 
Cuando estalló la huelga del algodón en 1933, Juan tenía trece años, sus padres eran cosechadores y se habían unido a ella. El día que los empleadores atacaron a los huelguistas en Pixley él estaba en la escuela, ubicada frente a la antigua carretera 99, cuando escuchó un tiroteo. El director, el señor Rudeholm, pidió permanecer en la escuela hasta que hubiera pasado el enfrentamiento.

De su vida en Pixley recuerda cuán significativa fue la unidad del pueblo mexicano, pues en las tardes se reunían diferentes familias para comer. Un día una familia cocinaba una gran olla de frijoles y hacían tortillas para todos y al día siguiente se reunían en otro lugar, y así sucesivamente. Para él, mediante esa colectividad lograron mitigar el hambre.

\section{LA HUELGA DE ALGODÓN LLEGA A SU FIN}

La huelga terminó junto con el mes de octubre, entonces se estableció el aumento salarial de .60 a .75 centavos por 100 libras de algodón cosechadas. En parte esto se logró gracias a la mediación que realizó George Creel, de la National Recovery Administration, enviado por el gobierno de Roosevelt después de los hechos violentos de Pixley (Walker, 2012, p. 54). Sin embargo, como la misma Dana señaló, ello no significó el fin de las confrontaciones. Fue durante esta década cuando se avanzó en la consolidación del poder agroindustrial, gracias al amparo y al trabajo coordinado con diferentes instancias de gobierno.

El CAWIU aceptó a regañadientes el aumento salarial, y aún sin el reconocimiento sindical, la huelga del algodón fue considerada, aunque tibia, una victoria laboral. El Partido Comunista de California asumió el mérito de este pequeño triunfo, lo cual se vislumbró en una entrevista a Sam Darcy, organizador de distrito 13 del Partido cuando se presentó como un estratega a la sombra. Pero según Pat Chambers, Caroline Decker y los trabajadores del algodón, Darcy malinterpretó la naturaleza del CAwıU en el campo y subestimó la contribución de los trabajadores en el desarrollo de la estrategia local (Weber, 1986, p. 205).

Sam Darcy tenía poco conocimiento del terreno, ¿cómo podría tener una comprensión clara del espacio sin tener una presencia constante en él? Para ello se debe hilar fino y hablar sobre las características del sindicato. Esta era una organización en ciernes, creada recién en 1931, sin recursos, y que con- 
taba con muy pocos organizadores de huelga para trabajar en todo el Valle de San Joaquín, el cual era "una zona gigantesca que se extendía a través de seis condados, un área de 114 millas de largo, 30 a 40 millas de ancho, salpicado con más de 2000 fincas" (Meister y Loftis, 1977, p. 30 citado por Chacon, 1984, p. 340). Por lo cual el funcionamiento real de la organización sindical dependía en gran medida del trabajo realizado en las comunidades y de la cercanía existente entre los trabajadores (véase Weber, 1986).

El organizador sindical Porter M. Chaffee, narró para la Federal Writers Project, en un documento inédito, cómo era el trabajo de un organizador del TUUL: recibían poco o ningún salario, eran los simpatizantes de la organización quienes solían alimentarlos y en ocasiones les donaban algunos pesos. Para trasladarse viajaban en automóviles destartalados, haciendo autostop o en vagones de carga. Cuando no había huelgas visitaban las chozas de los trabajadores migratorios que solían acampar a lo largo de las orillas del arroyo o en los bordes de los campos y huertos de cultivo. Ellos eran los encargados de recabar información sobre salarios, condiciones de trabajo y quejas, en torno a las cuales esperaban desarrollar una lucha (Chaffee, sin publicar, p. 119 citado por Jamieson, 1945, p. 88).

Además de la participación activa de los trabajadores agrícolas, Weber (1986, p. 161) afirma que se establecieron comités de huelga, compuestos por voceros locales, quienes de forma cotidiana iban tomando decisiones tácticas sobre su desarrollo. Los voceros locales, al ser parte de la comunidad de trabajadores agrícolas, tenían un conocimiento sobre el trabajo, las condiciones laborales y las necesidades de los trabajadores, además, sabían la ubicación de los ranchos, conocían a los contratistas y a los empleadores inmediatos. En general, podían entender los deseos y aspiraciones de los trabajadores, que eran los propios. A pesar de ello, y a que representaban a la mayoría de los trabajadores movilizados no existió participación mexicana dentro de los escalafones del cAwiu.

Si bien el Partido Comunista, durante el tercer periodo, cambió de estrategia al crear sus propios sindicatos y adherir a sus filas a trabajadores de minorías étnicas discriminadas, al final su cometido seguía siendo llegar a la masa anglosajona. Chaffee contó que Darcy, ${ }^{26}$ a quien consideraba un hombre brillante, un "verdadero marxista", era cercano a los filipinos y quiso publi-

${ }^{26}$ Chaffer recuerda que, a principios de la década de los setenta, Sam Darcy vivía en Filadelfia donde dirigía una tienda de segunda mano (Jarrell, 2004, p. 73). 
car una declaración traducida al tagalo en The Western Worker, el periódico del Partido Comunista. Chaffer lo objetó al afirmar que algo así asustaba a los trabajadores estadunidenses. El texto fue eliminado de la edición (Jarrell, 2004, pp. 72 y 88 ).

Contrario a las desarticulaciones entre el Partido y la clase trabajadora, después de las huelgas de 1933 los productores agrícolas del estado se organizaron en torno la Asociación de Agricultores de California, "establecida en marzo de 1934 por la Cámara de Comercio de California y la Federación de la Oficina Farmacéutica de California en respuesta a la oleada de huelgas laborales [...] [con el objetivo de] romper futuras huelgas y mantener los intereses financieros de los grandes productores" (Mitchell, 1996, p. 174; Pichardo, 1995, p. 26 citado por Walker, 2012, p. 61).

Esta organización era una red que congregaba distintos intereses y producciones agrícolas, fue una reactualización de las organizaciones por producto que existen desde finales del siglo xIx y se han encargado tradicionalmente de la comercialización, el aumento de las ganancias, de la administración, así como de la consolidación de su poder político al ocupar puestos de gobierno.

Unos meses después del establecimiento de esta Asociación estalló la gran huelga de los estibadores en la bahía de San Francisco organizada por el Sindicato Industrial de Trabajadores Marinos (MwIU) sindicato comunista, adherido al TUUL. En ese contexto los Agricultores de California pagaron inserciones en la prensa alertando de la penetración comunista, tal vez temían que fuera una suerte de ola expansiva que llegara a otras ramas productivas del país.

El 20 de julio de 1934, la policía de Sacramento y los agentes del alguacil realizaron allanamientos a tres lugares de reunión de personas adheridas al Partido Comunista, donde confiscaron equipo de oficina, pancartas, literatura, alimentos, entre otros objetos con los cuales lograron llenar tres camiones. Además, destruyeron las oficinas de The Western Workers y quemaron la prensa Triagle, donde se imprimía ese periódico. ${ }^{27}$

Durante estas redadas dirigidas a estibadores, también fueron detenidos Pat Chambers y Carolin Decker, quienes fueron encarcelados en Sacramento acusados de sindicalismo criminal y vagancia. ${ }^{28}$ Además, vigilantes

27 The San Bernardino County Sun, 21 de julio de 1934, p. 2.

28 The San Bernardino County Sun, 21 de julio de 1934, p. 2. 
de las zonas agrícolas se unieron a estas acciones anticomunistas recogiendo a decenas de personas consideradas agitadores para después expulsarlos del condado. La mayoría de las veces estas detenciones se realizaron sin ninguna orden por parte de los tribunales. ${ }^{29}$

Las catorce personas detenidas durante las redadas vivieron un juicio largo que culminó el 1 de abril de 1935, el veredicto habló de ocho personas acusadas de conspiración: Martin Wilson, Nora Conking, Albert Hougardy, Jack Crane, Lorine Norman, Norman Mini, Carolin Decker y Pat Chambers quienes enfrentaron una pena de uno a catorce años de prisión, y seis personas fueron absueltas. Al respecto, el abogado defensor Leo Gallagher describió lo ocurrido como el resultado de la persecución política, con poca importancia real sobre el comunismo. ${ }^{30}$

En junio de 1937 el abogado de los encarcelados, R. W. Henderson, presentó una apelación a la sentencia, donde afirmó que los prisioneros fueron apresados no por un delito cometido, sino por la presunción y la posibilidad de provocar en el futuro actos violentos y antisistémicos. El abogado pidió al tribunal decidir si "un estatuto puede poner a hombres y mujeres en prisión porque abogan por la violencia cuando surja la necesidad en algún momento en el futuro remoto", ${ }^{31}$ al final Pat Chambers y Caroline Decker permanecieron dos años en prisión. Esta forma de enjuiciamiento no ha sido extraña dentro de la judicatura estadunidense, donde más que castigar la acción en sí, castigan la intención de la misma, como un acto de "prevención".

La ley de Sindicalismo Criminal fue utilizada para desarticular movimientos laborales, que pasaban por un momento importante, o que eran considerados una molestia. El castigo por un juicio de sindicalismo criminal comprendía una condena máxima de 14 años, y se penalizaba cualquier acto considerado como radical o terrorista. En California tan sólo la membresía a alguna organización considerada como prohibida, la posesión de literatura radical, documentos, canciones, o por el hecho de que alguien te denunciara podía ser suficiente para ser sujeto a juicio, incluso llegaron a utilizar testigos pagados, como Elbert Coutts, conocido delincuente que testificó en los jui-

${ }^{29}$ From a Staff Correspondent, "Summaty Justice Dealt Coast Reds. Courts in next two days will finish cases of 300 seized in strike raids", The New York Times, 23 de julio de 1934.

30 The Associated Press, "Eight coast reds convicted, 6 freed", The New York Times, 2 de abril de 1935 , pp. 1 y 5.

31 "Red chieftains admit urging violence "When Needed". Ask freedom", The Fresno Bee, 10 de junio de 1937, p. 14. 
cios de sindicalismo criminal en California durante la década de los veinte (White, 2006, pp. 718-719).

Además de estas acciones en 1935 fue disuelto el TUUL, y por tanto los sindicatos adheridos a él, como el CAwıU. ${ }^{32}$ Desde las capas altas del Comintern, los partidarios que se encontraban fuera de la URSS cuestionaron la pertinencia del tercer periodo, que veían como impedimento para organizar a los trabajadores industriales - por la división de clase que había generado entre los trabajadores de distintas corrientes de izquierda-. En ese sentido, Georgi Dimitrov, secretario general del Comintern, abogó por la creación de un frente popular que permitiera establecer coaliciones entre partidos de izquierda, idea que quedó establecida en el Séptimo Congreso de la Comintern, en agosto de 1935 (Cherny, 2002, pp. 10 y 11).

\section{UN SINDICATO SE FORTALECE}

La disolución del cawıu no significó la disminución o la eliminación de las luchas sindicales, ya que la precariedad laboral seguía presente. A la par de él coexistió un sindicato que finalmente se consolidó como su sucesor, la Confederación de Uniones de Campesinos y Obreros Mexicanos (сUсом), ${ }^{33}$ fundamental para la organización agrícola de California.

En algunos momentos el CAWIU y el CUOM, antecesor del CUCOM, tuvieron algunos desencuentros y disputas por el liderazgo de huelgas como la de El Monte Berry (1933). Entonces, Armando Flores (antiguo líder del СUоM) se disputaba con el CAwIU el control de la huelga, pero en una reunión celebrada el 7 de junio con los trabajadores en huelga Armando recibió

32 "El sindicato organizó y dirigió 51 huelgas de trabajadores mexicanos, otros hispanohablantes, filipinos y japoneses entre 1932 y 1934 ” (Maciel, 1989, p. 33).

${ }_{33} \mathrm{La}$ creación del cucom es incluso más antigua que el cAwIU, y tiene desde su origen una clara identidad étnica cuando en 1927, en una reunión en Los Ángeles, organizaciones como la Federación de Sociedades Mexicanas, de sociedades de ayuda mutua y sindicatos mexicanos, formaron la Confederación de Uniones de Obreros Mexicanos (CUOM), que en gran medida había sido impulsado por el cónsul Alfonso Pesquería -y a pesar de la renuencia del consulado a apoyar ideas "radicales"-, la herencia del PLM fue importante para el cuom, quien dijo tener principios anarquistas-sindicalistas. También tomó como modelo a la organización sindical mexicana CROM y, en 1933, se reagrupó y se convirtió en la Confederación de Uniones de Campesinos y Obreros Mexicanos (Cucom) (Balderrama, 1982, p. 92; Maciel, 1989, p. 31; Weber, 1986, pp. 128 y 310). 
el respaldo público del cónsul Alejandro V. Martínez, quien además se refirió a los mexicanos que estaban en el cAWIU como "rojos", y se negó a brindarles asistencia, ante esto el entonces vicecónsul, Ricardo Hill, hijo del general revolucionario Benjamín Hill, lo interpeló en público y refrendó su compromiso de apoyarlos (Balderrama, 1982, pp. 94-95).

Debido a este incidente y a la creciente enemistad entre ambos personajes, el cónsul de Los Ángeles, Alejandro V. Martínez, envió una carta con carácter de reservado al secretario de Relaciones Exteriores para solicitar que Ricardo Hill fuera reubicado en otra oficina. Como justificación aducía que Hill no cumplía a cabalidad las funciones otorgadas, además denunciaba que había dado declaraciones públicas a diarios como La Opinión donde manifestó su abierto resentimiento hacia él. ${ }^{34} \mathrm{Al}$ final, Hill fue trasladado y ascendido de vicecónsul a cónsul de cuarta a la oficina consular de Marsella, en Francia, en 1934.

Sin embargo, antes de su traslado participó activamente en la organización y consolidación del CUOM (después CuCOM). Los trabajadores agrícolas lo invitaron a formar parte de la transformación del grupo "de ex huelguistas en un sindicato formal. La reunión, celebrada el 15 de julio de 1933, produjo [esta] [...] nueva organización [...] y una alianza con el consulado" (Spaulding, 1934 citado en Balderrama, 1982, p. 97). Desde su creación este sindicato mantuvo un vínculo cercano con algunas instancias del gobierno de México y con organizaciones gremiales como la CROM, ${ }^{35}$ clave al momento de enfrentar los problemas que el traslado de Ricardo Hill a Marsella generó en la incipiente organización sindical.

Durante la formación del cucom decidieron que Ricardo Hill sería parte del organigrama, por lo cual tenía en su poder documentación y dinero del sindicato. El traslado de Hill a la capital para después ser enviado a Marsella significó un conflicto para el CUCOM, quien envió una carta (el 12 de diciembre de 1933) a Eucario León, secretario general de la CROM, para solicitar su intermediación para recibir los documentos y dinero requeridos y después enviarlos a las oficinas del sindicato en Los Ángeles, California. Entre lo solicitado estaban alrededor de 1200 cédulas de miembros activos del sindi-

${ }^{34}$ Carta del cónsul Alejandro V. Martínez al secretario de Relaciones Exteriores, 27 de septiembre de 1933, expediente personal de Enrique Bravo, 3a. parte, núm. 4919, exp. I/131/4977, AHGE-SRE, México.

${ }^{35}$ Quien les proporcionó ayuda económica en 1935 cuando el cucom lideró 6 de las 18 huelgas más grandes que estallaron durante ese periodo (Walker, 2012, p. 64). 
cato equivalentes a un dólar cada una. Un libro de banco en el cual constan las cantidades depositadas, la extensión de una carta poder para cambiar los giros postales que estaban a su nombre, entre otras cosas. ${ }^{36}$

Por otro lado, además de los reacomodos internos del sindicato, su fortalecimiento se da a la par del arribo de nuevos trabajadores a California: los okies. Llegaron al estado en momentos álgidos de las huelgas, no sólo por iniciativa personal, su movilidad fue estimulada por los empleadores que les generaron expectativas y se aprovecharon de su necesidad para pagarles menos de lo estipulado. Esta fue una estrategia recurrente utilizada para saturar el mercado y bajar los salarios. Con los mexicanos ya habían hecho lo propio, el 28 de octubre de 1933, el periódico The Press Democrat de Santa Rosa, había resaltado la responsabilidad de los agricultores del sur de California por la presencia de miles de mexicanos en campos y huertos. Cuando años atrás los alentaron a ingresar a Estados Unidos porque estaban dispuestos a recibir un salario menor que el de los trabajadores domésticos. ${ }^{37}$

En ese contexto, más allá del triunfo de clase de los trabajadores, fue la consolidación del poder de los agroindustriales sobre el mercado laboral agrícola lo que se fortaleció, además, el Programa Bracero que surgió a principios de los años cuarenta y constituyó en gran medida la reactualización de la figura de los esquiroles, que antes habían sido los migrantes recién llegados o los okies; todos ellos aceptaron trabajar en momentos de huelga por salarios inferiores.

\section{LA HUELGA DE LOS CÍTRICOS}

Una de las huelgas más significativas para el cucom fue la de los cítricos, la cual estalló el 15 de junio de 1936, en el condado de Orange en el Valle Imperial, donde la precariedad laboral había llegado a tal punto que incluso los empleados tenían que pagar por su equipo de trabajo (sacos, guates), y por el traslado a los lugares de recolección (Walker, 2012, p. 65).

${ }^{36}$ Carta del secretario general del сuсом, Armando Flores, al secretario general de la CROM, Eucario León, 12 de diciembre de 1933, expediente personal de Enrique Bravo, 3a. parte, núm. 292, exp. I/131/4977, AHGE-SRE, México.

37 "More trouble over strike", The Press Democrat, 28 de octubre de 1933, p. 10. 
Días antes de iniciar la huelga el sheriff del condado de Orange, Logan Jackson, había incautado un pliego con las demandas del sindicato, que según su parecer fueron llevadas al condado por agitadores de Los Ángeles, donde pedían .40 centavos por hora (en comparación con los .27 centavos que ya percibían), una jornada laboral de 8 horas, rechazar la contratación de menores de edad y mujeres, la desaparición del sistema de bonificaciones a cambio de quedarse con el trabajador toda la temporada, ${ }^{38}$ así como el derecho a no pagar por el transporte, las herramientas de trabajo y, por supuesto, el reconocimiento sindical.

En ese momento de huelga el cucom tenía como uno de sus líderes a Guillermo Velarde, un tendero quien provenía de una familia anarquista originaria de Arizona. Su padre, Fernando Velarde, formó parte del sindicato de trabajadores industriales del mundo (IWW) y fue editor de La Unión Industrial, primer periódico en español del Iww y quien apoyó al Partido Liberal Mexicano. ${ }^{39} \mathrm{Su}$ hermana Evelyn Velarde fue activista en el movimiento chicano de Los Ángeles y fue parte de las organizadoras de la Comisión Femenil Mexicana Nacional, Inc. (Weber, 2016, pp. 189 y 224), fundada posteriormente en la década de los setenta.

Cabe señalar que el сuсом logró identificar la importancia de las redes de apoyo de la comunidad mexicana y reconoció que su fortaleza era "su capacidad de utilizar las identidades étnicas y culturales de sus miembros y las conexiones de la familia para difundir el mensaje del sindicato y asegurarse apoyo en las huelgas" (Walker, 2012, p. 68).

38 "Garden grove trio held in market riots", Santa Ana Register, 28 de mayo de 1936, p. 2.

${ }^{39}$ Fernando Velarde había mantenido un apoyó constante al PLM, incluso ocultó en su casa a Ricardo y a Enrique Flores Magón, pero en 1915 rompió relaciones con ellos, al unirse a Armando Ojeda y a Juan Francisco Moncaleano, con quienes intentó crear en Los Ángeles una confederación de grupos revolucionarios. Ricardo Flores Magón negó su respaldo, y en el núm. 205 de Regeneración, el 6 de marzo de 1915, publicó una nota que tituló ¡Despechados!, donde acusa a Velarde de ser "un burgués que tiene propiedad raíz"; a Ojeda lo acusó de delatar a sus compañeros que junto con él participaron en el motín de día de navidad de 1913, a cambio de una reducción de sentencia, y por su culpa Pedro Castorena fue torturado; a Juan Francisco Moncaleano lo acusó de estupro y de proferir ataque al PLM, por tanto, "No aceptamos, porque no podemos celebrar pacto alguno con los traidores a los intereses de la clase trabajadora. Ellos, lo que quieren, es aprovecharse del prestigio del Partido Liberal Mexicano para poder salir a flote del cenagal en que se hallan sumergidos. El proletariado los desprecia, y quieren hacerse escuchar a la sombra del Partido Liberal Mexicano." Regeneración, núm. 205, 6 de marzo de 1915. Recuperado de http://archivomagon.net/obras-completas/ art-periodisticos-1900-1918/1915/1915-03/ 
A mediados de julio de 1936 existió un primer intento por llegar al final de la huelga, sin embargo, la facción del sindicato que respaldaba la dirigencia de Velarde y que se oponía tajantemente a la intromisión consular, no estuvo de acuerdo. Según el periódico Santa Ana Register del 18 de julio de 1936, un día antes el cónsul Ricardo Hill y el vicecónsul Lucas Lucio $[\text { sic }]^{40}$ estaban reunidos con trabajadores mexicanos del condado de Orange para firmar la propuesta de fin de la huelga que enviaron los productores y empacadores, pero Velarde llegó a la reunión y los acusó de tratar de engañar a los trabajadores. ${ }^{41}$

Los desencuentros del entonces cónsul Ricardo Hill con una de las facciones del CUCOM, comandada por Velarde -que al final fue la que prevaleció-, se debe según Weber (1986, p. 310) a que desde 1933 existieron claras divisiones entre los dirigentes, que se encontraban fragmentados entre la facción radical comandada por Guillermo Velarde, y la dirigida por Armando Flores y el cónsul mexicano Ricardo Hill, quienes se oponían a la participación comunista.

A pesar de la postura moderada de Hill, su mediación no fue vista con buenos ojos. Productores de naranja del condado de Orange se quejaron desde los primeros meses de 1936, ante la Oficina de Asuntos Mexicanos del Departamento de Estado, por la sindicalización de los trabajadores mexicanos y las actividades laborales que en favor de ellos había realizado el cónsul Hill, de quien advierten, a pesar de tratar de encubrir sus actividades "radicales", sigue siendo responsable de los levantamientos. ${ }^{42}$

A esos desencuentros se sumó el percance que Hill sufrió el 8 de agosto de 1936, en el marco de la actuación de la Orquesta Típica Miguel Lerdo de Tejada, con el teniente de la policía de Los Ángeles, California, Peter Delgado, quien lo insultó e intentó golpearlo. El incidente se resolvió cuando autorida-

${ }^{40}$ La prensa difundió la idea de que Lucas Lucio era vicecónsul, sin embargo, su cargo era el de presidente de la Comisión Honorífica en Santa Ana, California. Véase Informe de protección correspondiente al mes de mayo de 1935 presentado por el cónsul Joaquín Terrazas del 31 de mayo de 1935, Informes sobre protección, Consulado en Los Ángeles, exp. IV/241(04) (73-27) “35”/1, fol. 376, AHGE-SRE, México.

41 "Strike peace is prevented by agitator", Santa Ana Register, 18 de julio de 1936, pp. 17 y 18.

${ }^{42}$ Carta de S. H. Strathman al congresista Sam Collins de la cámara de representantes. 11 de junio de 1936, expediente personal de Enrique Bravo, 3a. parte, núm. 78, exp. I/131/4977, AHGE-SRE, México. 
des de ambos países otorgaron la razón a Hill, e incluso el jefe de policía de Los Ángeles, James E. Davis, presentó excusas por parte de esa dependencia. ${ }^{43}$ Tanto las quejas por parte de los productores, como el enfrentamiento con el teniente Delgado, fueron decisivos en el nuevo traslado de Hill a otro estado. Al respecto, el escritor y diplomático Luis Quintanilla ofreció a la Secretaría de Relaciones Exteriores una reflexión clarificadora al mencionar que sin la enemistad de los productores del condado de Orange hacia Hill su traslado no se hubiera concretado. ${ }^{44}$ Así, nuevamente Ricardo Hill vivió una experiencia como la de 1933: fue removido y ascendido. Esta vez fue enviado a San Antonio, Texas, como cónsul general. ${ }^{45}$ La reubicación de Hill fue posible en parte debido al visto bueno dado por Edward Reed, jefe de la División Mexicana en el Departamento de Estado y amigo cercano de Luis Quintanilla. ${ }^{46}$

En lo que respecta a las dificultades que trae consigo la labor consular, Quintanilla afirma que cuando existe una tradición de explotación sistemática sobre el trabajador mexicano, como en algunas regiones de Estados Unidos, los cónsules trabajan "entre la espada y la pared", ya que cuando no atienden los intereses de su colonia y sí los de grupos locales, esta se encargará de buscar su remoción; por otra parte, cuando trabaja en favor de su colonia se arriesgan a la ira de los industriales de la región, quienes también buscarían su traslado mediante sus influencias con autoridades locales. ${ }^{47}$

En ese sentido, Hill fue un cónsul querido y respetado por la colonia mexicana en Estados Unidos, ya que decidió darle prioridad a la mejora de las condiciones de los trabajadores agrícolas, que a la relación establecida con autoridades locales y empleadores; su perspectiva con respecto al servicio consular le granjeó "una gran aclamación en la colonia, y los residentes mayo-

${ }^{43}$ Carta al secretario de Relaciones Exteriores del 11 de septiembre de 1936, expediente personal de Enrique Bravo, 3a. parte, núm. 313, exp. IV/131/155, AHGE-SRE, México.

${ }^{44}$ Carta de Luis Quintanilla, s. f., expediente personal de Ricardo Hill, 1a. parte, núm. 6, exp. IV/131/155, AHGe-sRe, México.

${ }_{45}$ Carta de Manuel Cruz, jefe del Departamento a la Comisión Honorífica Mexicana, en Irwindale, Cal. E.U.A. 16 de octubre de 1936. Expediente personal de Enrique Bravo, 3a. parte, número 302, exp. IV/131/155. AHGE-SRE, México.

${ }^{46}$ Carta de Luis Quintanilla. S/F. Expediente personal de Ricardo Hill, 1a. parte, núm. 6, exp. IV/131/155; Carta de Luis Quintanilla. S/F. Expediente personal de Ricardo Hill. 1a. parte, núm. 6, exp. IV/131/155. AHGE-SRe, México.

${ }^{47}$ Carta de Luis Quintanilla, s. f., expediente personal de Ricardo Hill, 1a. parte, núm. 6, exp. IV/131/155, AHGE-SRE, México. 
res aún lo recuerdan con cariño". "Este hombre era un verdadero cónsul", recuerda uno de ellos (Balderrama, 1982, p. 108).

En este escenario de lucha de fuerzas, la huelga se extendió un poco más, y a pesar de llegar a su fin, los ataques que los Agricultores Asociados emprendieron contra el sindicato fueron aún más virulentos. En la prensa patrocinaron artículos que alertaban a la población sobre un "programa de penetración silenciosa" financiado por los comunistas, y advertían que más allá del descontento legítimo de los trabajadores agrícolas estaban los intereses del Partido Comunista de sembrar la discordia para sumar simpatías. The Chula Vista Star denunciaba en su artículo "Amenaza Comunista", cómo el Partido a través de su periódico The Western Workers pretendía "avivar las llamas de la amargura y odio entre los trabajadores agrícolas de California”. ${ }^{48}$

En la batalla mediática que libraron contra trabajadores agrícolas y organizadores sindicales, destaca la propaganda de descrédito hacia Guillermo Velarde, como la aplicación a conveniencia de estamentos jurídicos como la Vagrancy Law, ${ }^{49}$ la cual se caracterizó por ejercer un castigo selectivo a personas pobres, ya que penalizó la falta de trabajo, el merodeo, el juego, la prostitución, la adicción a las drogas, pero sobre todo fue un recurso utilizado contra personas políticamente molestas para grupos poderosos. Este estatuto buscó que el "vagabundo" siguiera su camino, para ello autoridades locales echaron mano del destierro forzado con el objetivo de sacar del condado a distintos organizadores sindicales.

Cuando Velarde y José Espinoza acompañaban a Fred West -representante de la Federación Estatal de Trabajo- en un viaje en automóvil por la ciudad de Fullerton, en el condado de Orange, investigando los acontecimientos violentos en la huelga de los cítricos, fueron detenidos y acusados de vagancia por lo cual se les fijó una multa de 1000 dólares. Al respecto el sheriff Jackson Logan, del condado de Orange, se quejaba de los problemas que Velarde había estado causando en la zona, ${ }^{50}$ a quien le siguieron sumando cargos mediante una estrategia de persecución judicial y mediática. Al cargo por vagabundeo le añadieron una orden de arresto a causa de una multa de tránsito. Lo acusa-

48 "Communistic threat", The Chula Vista Star, 7 de agosto de 1936, p. 2.

49 Este estatuto fue derogado en el marco de las protestas por los derechos civiles de la década de los sesenta.

50 "Labor leaders face vagrancy trial in south", Oakland Tribune, 15 de julio de 1936, p. 6. 
ban de conducir por el carril equivocado, por lo cual debía cubrir una multa de 250 dólares. ${ }^{51}$

El juicio contra Velarde y Espinosa por cargo de vagabundeo se realizó el 10 de agosto de 1936 en la corte del juez Halsey I. Spence, pero, después de cinco horas y media y sin un veredicto, el juicio se reprogramó para el 3 de septiembre. ${ }^{52}$ La dilación de la sentencia posiblemente obedeció a la revancha, como a la falta de un acuerdo del jurado ante la campaña de descredito hacia Velarde. El veredicto final se dio el 31 de diciembre de 1936 con una condena de 90 días en la cárcel por cargos de vagancia. Sin embargo, en 1937, cuando Velarde tenía 33 años, una nueva acusación se cernía sobre él, una menor de catorce años lo acusaba en el condado de Los Ángeles de cometer delitos morales graves en su contra. ${ }^{53}$ El desenlace sobre esa acusación no será aquí resuelto.

Después de la huelga de los cítricos, el cucom cortó su relación con el gobierno mexicano y sus cónsules, y la mayoría de sus miembros pronto se unieron a la AFL y otros más permanecieron bajo el liderazgo de Velarde hasta 1937, cuando se fusionaron con el Comité de Organización Industrial (cio) de John L. Lewis, miembro de la United Cannery, Agricultural, Packing y Allied Workers of America (UCAPAWA) (Walker, 2012, p. 68).

Como hemos observado hasta aquí, los mexicanos han constituido la columna vertebral de la fuerza laboral agrícola en Estados Unidos, pero sobre sus derechos poco se ha regulado. En 1935 fueron excluidos de la Ley Nacional de Relaciones Laborales (NLRA), que estableció el derecho de los trabajadores industriales a sindicalizarse, tampoco fueron contemplados en la Fair Labor Standards Act (FLSA) de 1938, que establecía el pago de horas extra, un tabulador de salario mínimo, una regulación sobre el trabajo infantil y la adscripción a la Ley de Seguridad Social. ${ }^{54}$

Después de la década de los treinta entraron en el escenario laborar los trabajadores temporales con el Programa Bracero, su instrumentalización se justificó con la escasez de mano de obra a causa de la guerra y el reacomodo

51 "Formal end to strike may be ordered today", Santa Ana Register, 24 de julio de 1936, p. 27.

52 "Velarde jury is unable to reach verdict", Santa Ana Register, 11 de agosto de 1936, p. 5.

53 "Girl Accuses S. A. Agitator", Santa Ana Register, 10 de febrero de 1937, p. 13.

${ }^{54}$ Es hasta 1975, con la Ley de Relaciones Agrícolas de California (ALRA), cuando los trabajadores agrícolas tuvieron elecciones de representación sindical libres de la interferencia del empleador. 
laboral por la industria bélica, sin embargo, más allá de esta "verdad" discursiva, lo que imperaba fue la necesidad de bajar nuevamente los salarios, que tal vez a causa de las distintas huelgas habían aumentado considerablemente. El Programa pronto fue visto por los trabajadores domésticos como una nueva forma de saturar el mercado y "reventar" las huelgas. Además, su administración en ambos países estuvo plagada de corrupción, y a pesar de las expectativas de los trabajadores, la realidad pronto fue evidente: la precariedad en las condiciones de vida y laborales siguió imperando.

\section{CONCLUSIÓN}

En este recorrido observamos que los lazos que los agroindustriales establecieron con funcionarios sirvieron para incidir en sus reacciones y acciones en momentos sensibles de las confrontaciones, las cuales decantaron tanto en la persecución jurídica, como en el menosprecio hacia los trabajadores y sus condiciones. Además, el capital económico de estos actores fue fundamental para poder difundir mediante el uso de la prensa la idea de que en el campo agrícola no existen problemas laborales sino agitadores externos. ${ }^{55}$

De forma específica podemos decir que, el arsenal de acciones de desprestigio que utilizaron hacia los líderes sindicales y funcionarios consulares afines a los sindicatos, fue una estrategia de control sobre este movimiento laboral y sus simpatizantes, a ello se sumó la saturación del mercado mediante el estímulo de la movilización de trabajadores, así como el control sobre el establecimiento de salarios y de las empresas relacionadas como financiadoras y productoras de insumos.

En general, observamos cómo los intensos movimientos por la organización sindical provocaron, además de una violencia desbordada hacia los trabajadores agrícolas y los sindicatos en formación, la reconfiguración de los actores en conflicto, como la de los agroindustriales, quienes continuaron estrechando lazos en los distintos espacios de poder de la sociedad californiana, y lograron consolidarse como un grupo unificado mediante el establecimiento de la Asociación de Agricultores de California. Asimismo, advertimos que la experiencia de lucha de los trabajadores, y sobre todo la cercanía que existía entre ellos gracias a las experiencias compartidas, a su pertenen-

55 Para mayor información véase Galarza (1977). 
cia étnica, como a su participación previa en otro tipo de organizaciones, les permitió, en cierta medida, sortear la violencia física como estructural que ejercieron contra ellos.

\section{LISTA DE REFERENCIAS}

Acuña, R. (2007). Corridors of migration: The odyssey of Mexican laborers, 1600-1933. Estados Unidos: The University of Arizona Press.

Amstutz, D. (1985). U. S. farm policy and international agricultural markets. Case Western Reserve Journal of International Law, 17(3), 321-333. Recuperado de https:// scholarlycommons.law.case.edu/jil/vol17/iss3/1

Balderrama, F. E. (1982). In defense of La Raza. The Los Angeles Mexican Consulate and the Mexican community, 1929 to1936. Arizona: The University of Arizona Press.

Barry, R. P. (ed.) (1938). A documentary history of migratory farm labor in California. Oakland, California: Federal Writers Project.

Chacon, R. (1984). Labor unrest and industrialized agriculture in California: The case of the 1933 San Joaquin Valley cotton strike. Social Science Quarterly, 65(2), 336-353.

Cherny, R. W. (2002). Prelude to the popular front: The Communist Party in California, 1931-1935. American Communist History, 1(1), 5-42.

Cletus, D. (1981). Bitter Harvest, a history of California farmworkers, 1870-1941. Ithaca: Cornell University Press.

Fraser, S. (2010). El sindicalismo estadounidense y la Gran Depresión. Boletín Internacional de Investigación Sindical. Crisis financieras, deflación y respuestas de los sindicatos. ¿Cuáles son las enseñanzas? 2(1), pp. 9-26.

Galarza, E. (1977). Farm workers and agri-business in California, 1947-1960. Indiana: University of Notre Dame Press.

González, G. G., (1994). Labor and community: Mexican citrus worker villages in a southern California county, 1900-1950. Illinois: University of Illinois Press.

González, G. G. (1999). Mexican consuls and labor organizing imperial politics in the American southwest. Austin, Texas: University of Texas Press.

Hobsbawm, E. (2014). Historia del siglo xx. México: Editorial Crítica.

Jamieson, S. M. (1945). Labor unionism in American agriculture. Bulletin of the United States Bureau of Labor Statistics, 836. Recuperado de https://fraser.stlouisfed.org/ title/4306 
Jarrell, R. (1992). Helen Hosmer: a radical critic of California agri-business in the 1930s. Santa Cruz, California: University of California/University Library, Agricultural History of Santa Cruz County. Recuperado de https://escholarship.org/uc/item/ 01d1b4q 4

Jarrell, R. (2004). Porter Chaffee: labor organizer and activist, 1900-1977. Santa Cruz, California: University of California/University Library Agricultural History of Santa Cruz County. Recuperado de https://library.ucsc.edu/reg-hist/chaffee

Leeman, J. (2016). La clasificación de los latinos y latinas en la historia del censo de los Estados Unidos: la racialización oficial de la lengua española. En J. del Valle (ed.), La historia política del español (pp. 354-379). Madrid: Editorial Aluvión.

Maciel, D. (1989). Al norte del Río Bravo (pasado inmediato) (1930-1981). México: Editorial Siglo XXI.

Massey, D. S. (2008). La racionalización de los mexicanos en Estados Unidos: estratificación racial en la teoría y en la práctica. Migración y desarrollo, 10, 65-95. Recuperado de http://www.scielo.org.mx/scielo.php?script=sci_arttext\&pid=S1870$75992008000100004 \& \operatorname{lng}=\mathrm{es} \& \ln \mathrm{ln}=\mathrm{es}$

Mitchell, D. (1996). Lie of the land: Migrant workers and the California landscape. Minnesota: University of Minnesota Press.

Morison, S. E. et al. (1995). Breve historia de los Estados Unidos. México: FCE.

Omi, M. y Winant, H. (2015). Racial formation in the United States. Nueva York: Routledge.

Schwartz, H. (1998). John Sanchez oral history transcript. California: Labor Archives and Research Center, Universidad Estatal de San Francisco. Recuperado de https:// archive.org/stream/csfst_000027t/Sanchez\%20Oral\%20History\%20LARC_djvu.txt

Walker, D. (2012). The failure of the agricultural labor movement in California, 1930-1942. (Thesis Master of Arts in Humanities). California State University Dominguez Hills, Estados Unidos.

Weber, D. (1986). The struggle for stability and control in the cotton fields of California: Class relations in agriculture, 1919-1942. (Tesis de doctorado). UCLA.

Weber, D. (1996). Dark wweat, white gold California farm workers, cotton, and the New Deal. Oakland, CA: University of California Press.

Weber, D. (2016). "Different plans": Indigenous pasts, the Partido Liberal Mexicano, and questions about reframing binational social movements of the twentieth. Social Justice, 42(3-4).

White, A. A. (2006). The crime of economic radicalism: Criminal syndicalism laws and the industrial workers of the world, 1917-1927. Colorado: University of Colorado Law School. 


\section{OTRAS FUENTES}

\section{Archivos}

AHGE-SRE Archivo Histórico Genaro Estrada-Secretaría de Relaciones Exteriores, México.

\section{Hemerografía}

Oakland Tribune, 1933, 1936.

Santa Ana Register, 1936, 1937.

Santa Cruz Sentinel, 1933.

The Bakersfield Californian, 1933.

The Chula Vista Star, 1936.

The Fresno Bee, 1937.

The New York Times, 1934, 1935.

The Press Democrat, 1933.

Ukiah Republican Press, 1934. 